\title{
LE, Rat Strain
}

National Cancer Institute

\section{Source}

National Cancer Institute. LE, Rat Strain. NCI Thesaurus. Code C76188.

Derived by Long and Evans (1915) by crossing female Wistar rats with a wild gray male, the Long-Evans rat was disseminated to Charles River from Canadian Breeding Farm and Laboratories (1978). This outbred rat breed is white with a black or brown hood. The Long-Evans rat is utilized in a variety of research applications including obesity and behavioral research. 